\title{
Effect of Qualification in ICT, Age and Income on Use of Computers among Postgraduate Students in Makerere University School of Education
}

\author{
Bakkabulindi F. E. K., Sekabembe B., Shopi J. M. \& Kiyingi G.
}

The purpose of this study was to establish the relationship between: qualification in using ICT, age and level of income; and use of computers among postgraduate students in Makerere University School of Education. The study was carried out following a cross-sectional survey design and involved 69 students. Primary data, which were collected using a self-administered questionnaire, were analysed using summary statistics, t-test, analysis of variance, correlation and multiple regression analyses. The study found an insignificant relationship between possession of qualifications in using ICT and the use of computers; a significantly negative relationship between age and the use of computers; and a significantly positive relationship between level of income and the use of computers. It was, therefore, concluded that possession of qualifications in using ICT is not sufficient to enhance the use of computers; age can negatively affect the utilisation of computers; and income enhances the utilisation of computers. Thus, it is recommended that, to enhance the use of computers among the said students, relevant managers should give special ICT training to the older students; and provide access to computers, to ensure that students whose incomes do not enable them to acquire personal computers have access.

Key words: ICT; Personal characteristics; Innovation adoption; Makerere University

\section{Introduction}

To survive, organisations have to foster the adoption of innovations among their members (Mullins, 2002). One innovation that is particularly important for organizational survival today is the use of computers, given its innumerable benefits. In Makerere University, however, the use of computers by students has been reported to be low (see, for example, Nassanga, 2001). This failure to make optimal use of computers by students in the University leads to several undesirable outcomes such as wastage of funds the University and its donors have sunk on underutiised or even unutilised facilties (Njiraine, 2000). Besides, in ignoring computer facilities, especially in the learning process, students deny themselves benefits of digital technolgy-based learning such as increased interst, simulated life situations and studying at own paces (Kasozi, 2002). Though several studies (e.g. Nassanga, 2001) have documented low levels of use of computers by students at the University, few have looked into the reasons why the level of use of computers is low, despite the fact that if it is to be enhanced, the factors affecting it have to be well understood. Since individual characteristics may be among these factors (Rogers, 2003), this study was undertaken to appraise the role of three individual characteristics, namely, training and/

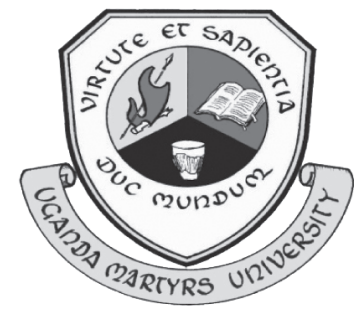

Journal of Science and Sustainable Development Copyright (C) 2009 Uganda Martyrs University ISSN: 2070-1748; Vol 2 (1): 51-57 www.umu.ac.ug 
or qualification in using ICT; age; and level of income in influencing computer use, taking the case of postgraduate students in the University's School of Education.

Ntulume (1998) defines training as the systematic modification of the behaviour of trainees, through teaching and learning. It is directed at changing people's knowledge, experience, skills and attitudes. It enables employees to be adaptable and, as technological advances continue, it enables them to cope with the changes (Wamala, 1996). In particular, it develops ICT literacy (Kibera, 1997). Niwe (2000) found lack of training as a major constraint to Internet use among academic staff in Makerere University. Similarly, Mwanja (2001) and Wakanyasi (2002) found inadequate training as a principal inhibitor of effective computer use in government ministries in Uganda and Nkumba University respectively while Zziwa (2001) reported lack of ICT training as the main problem curtailing effective utilization of computers in the management of students' information at Makerere University. Though these studies report a positive relationship between training and use of computers, none of those on Makerere University dealt specifically with postgraduate students. Thus, this study had sufficient ground to subject the hypothesis that there was a significant relationship between ICT training and use of computers by postgraduates in Makerere University to test, using a random sample of postgraduate students.

Schiffman and Kanuk (2004) observe that the age of consumer innovators is related to the product category in which the consumers innovate, with innovators tending to be younger than late adopters. Age is also theorized to be important in the adoption of health and/or demographic innovations such as family size planning (Mayanja, 2001; Turyahebwa, 2000). It is also theorized to be important in the adoption of agricultural innovations. In this regard, however, there are two conflicting explanations. For example, Basisa (1999) points out that while older farmers may have more experience and farm resources, thereby having strong incentives to try out emerging technologies, young farmers might have more schooling and exposure to new ideas that may help in the adoption of new technologies. As well, Ehikhamenor (1999) found age to have no influence on ICT cognition, thereby differing from other researchers that link age to the adoption of innovation. Such contradicting findings call for more studies. Moreover, of all these studies, only Ehikhamenor (1999)'s study was on the context of an academic institution (and even then not Makerere University). Thus, the question of whether age affected use of computers by postgraduates in Makerere remained to be answered.

Regarding income, Schiffman \& Kanuk (2004) observe that early adopters of innovations have higher incomes than late adopters. Indeed, according to Morales-Gomez \& Melesse (1998), access to the Internet and other ICTs is only open to a small fraction of the population, a phenomenon which is a function of income. They further observe that the situation is even more dramatic in developing countries, where the income gap is wide; literacy rates are remarkably low; and users of telecom technologies belong to the elite. Level of income has also been found to affect the adoption of other innovations. For example, Mugweri (2000) established the availability of funds as one of the challenges affecting the adoption of ICT networks in the Ministry of Finance, Planning and Economic Development while Omona (2001) found cost as one of the problems affecting the functioning of ICT facilities in the dissemination of information in selected health institutions in Kampala District. Mwanja (2001) also reported start-up costs as a significant factor affecting effective computer utilization in government ministries in Uganda while Nafuna (2002) found that the costs associated with acquiring, installing, and maintaining Internetrelated equipment had affected the adoption of the technology in Uganda. Njiraine (2000) reported high charges as having discouraged students and other users from making use of the Internet in Jomo Kenyatta Memorial Library, University of Nairobi and US International University of Africa Library in Kenya. Matovu (2003) also reported cost as one of the factors hindering the acquisition of ICT facilities. Whereas all these studies suggested relationship between income and the adoption of innovations, none 
of them was on Makerere University; hence the justification for testing whether income correlated with the adoption of computer use at the University. From the foregoing literature, therefore, the researchers sought to verify the hypotheses that: qualification in using ICT; age; and level of income enhance the use of computers.

\section{Method}

Using a correlation survey design, data were collected from a random sample of 69 postgraduate students. This was done using a self-administered questionnaire, with four background questions of relevance to the study, namely, course of study, possession of qualifications in using ICT, age, sex and level of income; five questions on use of computer hardware $(\alpha=.826)$; eight questions on use of computer software $(\alpha$ $=.825)$; and 11 questions on use of communication ICT facilities $(\alpha=.796)$. According to Cronbach's Alpha Coefficient Test (Cronbach, 1971), the questionnaire was reliable for the study, since the alpha coefficients for all its sections were above 0.5. Details about the respondents are given in Table 1.

Table 1: Distribution of Respondents by Study Program, Age, Gender and Level of Income

\begin{tabular}{|c|c|c|c|}
\hline Description & Category & Frequency & Percentage \\
\hline \multirow{5}{*}{ Program } & MEd* $^{*}$ & 38 & 55 \\
\hline & MEd ICT & 3 & 4 \\
\hline & MA Education Management & 19 & 28 \\
\hline & MA Education Policy \& Planning & 5 & 7 \\
\hline & MSc Human Resource Mgt & 4 & 6 \\
\hline \multirow{3}{*}{ Age group in years } & Up to 25 & 7 & 10 \\
\hline & 25 but below 40 & 54 & 81 \\
\hline & 40 and above & 6 & 9 \\
\hline \multirow{2}{*}{ Sex } & Female & 31 & 45 \\
\hline & Male & 38 & 55 \\
\hline \multirow{3}{*}{ Income level } & Low & 22 & 32 \\
\hline & Medium & 45 & 66 \\
\hline & High & 1 & 2 \\
\hline
\end{tabular}

${ }^{*}$ Curriculum, Teaching \& Media; Foundations of Education; Language \& Literature; Psychology; Science; Social Science \& Arts

The data were analysed using means, standard deviations, student $t$ test, Analysis of Variance (ANOVA), Correlation and Multiple Regression analyses.

\section{Findings}

Use of computers was a multi-dimensional variable made up of various components. For each of the components, the respondents ranked their level of use on a scale in the order " 1 "=Very rarely; "2"=Rarely; " $3 "=$ Neither rarely nor regularly; "4"=Regularly; and "5"=Very regularly. The findings are summarised in Table 2. 
Table 2: Utilization of Computers

\begin{tabular}{|c|c|c|c|}
\hline Component & & Mean & $\begin{array}{l}\text { Standard } \\
\text { deviation }\end{array}$ \\
\hline \multirow{5}{*}{ Hardware } & $\mathrm{PC}$ in general & 3.06 & 1.33 \\
\hline & Printers & 2.64 & 1.35 \\
\hline & Scanners & 1.64 & 1.04 \\
\hline & PC CD-ROM \& Multimedia components & 2.12 & 1.36 \\
\hline & PC zip drive & 1.48 & 0.85 \\
\hline \multirow{8}{*}{ Software } & Operating system software & 2.99 & 1.40 \\
\hline & Utility software & 2.36 & 1.51 \\
\hline & Word processing software & 3.36 & 1.38 \\
\hline & Spread sheet software & 2.16 & 1.11 \\
\hline & Database Mgt software & 1.61 & 0.84 \\
\hline & Graphics software & 1.74 & 0.95 \\
\hline & Desktop Publishing & 1.51 & 0.82 \\
\hline & Data analysis software & 1.41 & 0.77 \\
\hline \multirow{11}{*}{$\begin{array}{l}\text { ICT } \\
\text { communication } \\
\text { facilities }\end{array}$} & LAN in school & 2.29 & 1.37 \\
\hline & WAN in Makerere University & 2.20 & 1.24 \\
\hline & Africa Virtual University & 1.28 & 0.68 \\
\hline & Email & 3.36 & 1.45 \\
\hline & Web surfing & 3.45 & 1.30 \\
\hline & Bulletin board, mailing lists, discussion groups & 1.64 & 1.03 \\
\hline & Computer conferencing systems & 1.23 & 0.57 \\
\hline & Video conferencing systems & 1.23 & 0.60 \\
\hline & Electronic journals \& newsletters & 1.80 & 1.07 \\
\hline & Electronic databases & 1.61 & 1.00 \\
\hline & On-line library catalogues & 1.88 & 1.17 \\
\hline
\end{tabular}

The results in Table 2 suggest that computer hardware was rarely used by the respondents, with the item scoring highest (PC in general) having a mean of 3, which corresponds to neither rare nor regular use. To get an overall picture of how respondents rated themselves on hardware use, an average index "Hardware" was computed from the responses to the five questions on the utilisation of hardware and found to have a mean of 2.19, which, as per the scale used, confirmed that most respondents rated themselves below average in the use of hardware facilities. Regarding software, word processing had the highest sample mean, slightly above 3, followed by operating system software, implying that, these are the most used forms of software. Data analysis software (e.g. SPSS) had the lowest sample mean, slightly above 1, suggesting that this form of software was the least used. Overall, therefore, the results in Table 2 suggest that software was rarely utilized by the respondents. To get an overall picture of the respondents' self-rating on use of software, an average index "Software" was computed from the responses to the eight questions on the use of software. This was found to have a mean of 2.14 , meaning that majority of the respondents rarely used software. On the side of ICT communication facilities, surfing the internet had the highest mean (3.45). This was followed by email use (3.36). This suggests that the respondents used the two regularly. Conferencing had the lowest mean (1.23), meaning that majority of the respondents rarely used it. To get an overall picture of how the respondents rated their use of ICT communication facilities, an average index "Comm" was computed from their responses to the 11 questions on the use of communication facilities and found to have a mean of 1.97. This suggested that majority of the respondents rarely used these facilities. Finally, an overall average index labelled "Computer" was computed from the three indices (i.e., "Hardware", "Software" and "Comm") and was 
found to have a mean of 2.1. And going by the scale that was used, this suggested that majority of the respondents rarely used computers.

To test the hypothesis that qualification in using ICT enhances the use of computers, the respondents were asked to specify whether they possessed training in using ICT. Subsequently, they were categorised into those that possessed training in using ICT and those that did not. Thereafter, mean scores on the use of computers were computed for each of the groups. The findings were that the mean score for those that had training in using ICT was 2.27 while that for those that did not have training in using ICT was established at 1.97. To establish the significance of the mean differential, these results were subjected to a student $\mathrm{t}$-test. The results were that $\mathrm{t}=-1.91, \mathrm{p}=.06$, leading to the decision to accept the null hypothesis, meaning that training in using ICT did not significantly affect the use of computers. To test the hypothesis that age affects the use of computers, the findings on the respondents' age and use of computers were correlated, using Pearson's Correlation Coefficient Test. The results were that $\mathrm{r}=-.38, \mathrm{p}=.001$, leading to the decision to reject the null hypothesis. This means that there was a significant inverse relationship between age and the use of computers. Finally, to verify the relationship between level of income and use of computers, analysis of variance in the respondents' scores on use of computers by level of income (which was categorised as "Low", "Medium" or "High") was conducted. The results are presented in Table 3.

Table 3: ANOVA in Utilisation of Computers by Level of Income

\begin{tabular}{llllll}
\hline Level of income & $\mathbf{n}$ & Mean & Standard deviation & $\mathbf{F}$ & $\mathbf{p}$ \\
Low & 22 & 1.86 & 0.67 & 2.09 & 0.132 \\
Medium & 45 & 2.20 & 0.63 & & \\
High & 1 & 2.32 &. & & \\
Total & 68 & 2.09 & 0.65 & & \\
\hline
\end{tabular}

Table 3 shows that the use of computers tended to increase with level of income; nonetheless, F was established at 2.09, $\mathrm{p}=.132$. This led to the decision to accept the null hypothesis, meaning that there was no significant relationship between level of income and utilisation of computers.

The foregoing results suggested that age was the only significant correlate of utilisation of computers among the respondents. To establish the 'real' correlates, Multiple Regression Analysis, which took simultaneous relationships of all the variables into account, thereby documenting collective effects and accounting for potentially spurious factors (Sweet \& Grace-Martin, 2003), was used. Because of its categorical nature, a dummy was created for the variable "possession of an ICT qualification" as follows: $0=$ none; and $1=$ yes. On the other hand, age and level of income were used as given by the respondents, since the questions that were raised on them elicited continuous data. Multiple regression of the aggregate computer use index (i.e., "Computer") on the individual characteristics (i.e., training in use of ICT, age and level of income) returned an F-statistic of 7.25, p =.000, with a corresponding adjusted $\mathrm{R}$ square of .224 . This suggested that, collectively, the three individual characteristics influenced the use of computers $(p<.01)$, accounting for $22 \%$ of the variation in the use of computers among the respondents (adjusted $\mathrm{R}$ square $=.224$ ). The regression coefficients for the individual characteristics were as follows: qualification in using ICT, $r=0.219, \mathrm{p}=0.052$; age, $\mathrm{r}=-0.378, \mathrm{p}=0.001$; and level of income, $\mathrm{r}=0.241, \mathrm{p}=0.033$. This suggested that only age and level of income were significant correlates of computer use among the respondents $(\mathrm{p}<0.05)$ and that age was the most significant (smallest $\mathrm{p})$. 


\section{Discussion and Conclusions}

The study suggested that the use of computers among the respondents was low, thereby corroborating earlier researchers (e.g. Nassanga, 2001) that came to a similar finding about Makerere University. Nevertheless, the hypothesis that qualification in using ICT enhances the use of computers was not supported by the findings. Thus, the study is at variance with Fedorowicz and Gelinas (1998), Mwanja (2001) and Wakanyasi (2002), who found that adaptability to technological advances is a function of training. Though this (anomalous) finding could have resulted out of investigating the respondents' possession of ICT training albeit in a way that fell short of probing the level of training possessed, in the meantime, the study has ground to conclude that possession of ICT qualifications is inadequate to enhance the use of computers. The findings concurred with the hypothesis that age is inversely related to computer use, which is consistent with several past studies (e.g. Turyahebwa, 2000). This finding rhymes well with theoreticians like Schiffman and Kanuk (2004), who observe that age is an important correlate of innovation adoption. It is, therefore, recommended that, to enhance the utilisation of computers among postgraduate students in the School of Education, relevant managers should give special ICTrelated support to the older students. Level of income correlated with the adoption of ICT, a finding similar to that of several other studies (e.g. Matovu, 2003; Mugweri, 2000; Mwanja, 2001; Nafuna, 2002; Njiraine, 2000; Omona, 2001). This appears to be due to the fact that, often, the higher the income, the easier it is for individuals to acquire personal ICT facilities and to get exposure to ICT through various media such as magazines and newspapers (Moralez-Gomez and Melesse, 1998). It is, therefore, recommended that the managers of the School of Education avail computers, so that students that cannot afford personal computers can use the ones provided by the School.

\section{References}

Basisa, M. C., 1999. Farmer characteristics influencing the adoption of organic farming techniques among the partner farmers of Africa 2000 Network in Kasese District Uganda. Unpublished Msc. dissertation. Kampala: Makerere University.

Cronbach, L. J., 1971. Test validation. In: R. L. Thorndike, ed. 1971. Educational measurement. Washington D. C.: American Council on Education, pp. 443-597.

Ehikhamenor, F. A., 1999. Cognitive information foundation of university students: index of ICT in Nigeria. Information Technology for Development, 8 (3), pp. 134-144.

Fedorowicz, J. \& Gelinas, U. J. Jr., 1998. Adoption and usage patterns of COBIT: results from a survey of COBIT purchases. Information systems Audit \& Control Journal, 6, 45-51.

Kasozi, A. B. K., 2002. Contemporary issues in education: global forces that impact on East African education and affect local empowerment. In: Inter-University Council of East Africa Conference on contemporary issues in education: globalisation and local empowerment. Kampala, Uganda 16-17 September 2002. Makerere University: Kampala.

Kibera, F. N., 1997. Critical review of theories of adoption of innovations. Makerere Business Journal, pp.195-204.

Matovu, J., 2003. Information technology issues in Uganda's education sector. Uganda Journal of Education, 4, pp. 9-23.

Mayanja, S. P., 2001. Barriers to utilization of mother-to-child package in selected districts in Uganda. Unpublished MA dissertation. Kampala: Makerere University.

Moralez-Gomez, D. \& Melesse, M., 1998. Utilising information and communication technologies for development: social dimensions. Information Technology for Development, 8 (1), pp. 3-13. 
Mugweri, R. A., 2000. An assessment of the opportunities and challenges of exploiting ICT networks to improve efficiency and effectiveness in government operations: a case study of Ministry of Finance Planning and Economic Development. Unpublished Msc. dissertation. Kampala: Makerere University.

Mullins, L. J., 2002. Management and organisational behaviour. London: Pitman.

Mwanja, J., 2001. Computerisation in government ministries in Uganda. Unpublished MA dissertation. Kampala: Makerere University.

Nafuna, S. A., 2002. Impact of Internet Service Providers (ISPs) on electronic information provision in Uganda: a study of selected ISPs in Kampala. Unpublished Bachelor of library and information science dissertation. Kampala: Makerere University.

Nassanga, M., 2001. Students' participation in ICT usage and management: a case study of East African School of Library and Information Science. Unpublished Bachelor of librarianship and information science dissertation. Kampala: Makerere University.

Njiraine, D. M., 2000. Underutilization of Internet facilities at universities: a case study of Jomo Kenyatta Memorial Library (JKML), University of Nairobi and United States International University of Africa (USIUA) Library. Unpublished Msc dissertation. Kampala: Makerere University.

Ntulume, A. L., 1998. Training programmes and workers' performance: a case study of Uganda Posts and Telecommunications Corporation. Unpublished MA dissertation. Kampala: Makerere University.

Omona, W., 2001. Impact of information and communication technology (ICT) in accessing and disseminating health information in selected health institutions in Kampala District, Uganda. Unpublished Msc dissertation. Kampala: Makerere University.

Rogers, E. M., 2003. Diffusion of innovations. $5^{\text {th }}$ ed. New York: Free Press.

Schiffman, L. G. and Kanuk, L. L., 2004. Consumer behaviour. $8^{\text {th }}$ ed. New Delhi: Prentice-Hall of India.

Sweet, S. A. and Grace-Martin, K., 2003. Data analysis with SPSS: a first course in applied Statistics. $2^{\text {nd }}$ ed. Boston: Alyn \& Bacon.

Turyahebwa, E. G., 2000. Factors affecting knowledge, attitude and practice of modern contraception among women in Kampala District. Unpublished MA dissertation. Kampala: Makerere University.

Wakanyasi, N., 2002. Capacity utilization of information technology in organisations: a case study of Nkumba University. Unpublished MBA dissertation. Entebbe: Nkumba University.

Wamala, B. F., 1996. Management training and performance: factors that hinder the transfer of skills. Unpublished MBA dissertation. Kampala: Makerere University.

Zziwa, G., 2001. Computer utilization in the management of students' information at Makerere. Unpublished Msc dissertation. Kampala: Makerere University.

\section{ABOUT THE AUTHORS}

BAKKABULINDI, F. E. K. and SEKABEMBE, B. work at the East African Institute of Higher Education Studies \& Development, Makerere University, Kampala Uganda; SHOPI, J. M. works at Kigali Institute of Education, Kigali, Rwanda while KIYINGI, G. works at Canon Apollo Teachers' College, Fort Portal, Uganda. For correspondence on this article please contact: bsekabembe@educ.mak.ac.ug 
